\title{
Hipertrofik kardiyomiyopatili hastaların risk sınıflandırmasında görüntüleme yöntemlerinin yeri
}

\author{
The role of cardiac imaging modalities in risk stratification of patients with hypertrophic \\ cardiomyopathy
}

Kamil Tülüce ${ }^{1}$ Sadık Volkan Emren ${ }^{2}$ Selcen Yakar Tülüce ${ }^{2}$ Cemil Gürgün ${ }^{3}$ Cahide Soydaş Çınar ${ }^{3}$

${ }^{1}$ Karşıyaka Devlet Hastanesi, Kardiyoloji Kliniği, İzmir, Türkiye

${ }^{2}$ Atatürk Eğitim ve Araştırma Hastanesi, Kardiyoloji Kliniği, İzmir, Türkiye

${ }^{3}$ Ege Üniversitesi Tıp Fakültesi, Kardiyoloji Anabilim Dalı, İzmir, Türkiye

\section{Öz}

Hipertrofik kardiyomiyopati (HKM) genetik geçişli bir kalp hastalığıdır. Genç sporcularda ani kardiyak ölümün (AKÖ) en sık nedenidir. Bu ölümlerin önlenebilmesi için hekimler büyük özen göstermektedir. Ani kardiyak ölüm açısından yüksek riskli hastalar implante edilebilen kardiyoverter defibrilatör tedavisi için adaydırlar. Ani kardiyak ölüm açısından yüksek riskli bu bireylerin saptanabilmesi için yapılan risk sınıflandırmasında kardiyak görüntüleme yöntemleri önemli bilgiler sağlamaktadır. Görüntüleme yöntemleri ile elde edilen bilgilerin doğru yorumlanması ve önlemlerin alınması bu hastalar için hayat kurtarıcı olması nedeniyle büyük önem taşımaktadır. Teknolojideki gelişmeler yüksek riskli hastaların erken tespitine önemli katkılar sağlamaktadır. Bu derlemede biz HKM'li hastaların risk sınıflandırmasında görüntüleme yöntemlerinin yeri ve önemini değerlendirdik.

Anahtar Sözcükler: Hipertrofik kardiyomiyopati, ani kardiyak ölüm, kalp görüntüleme yöntemleri.

\begin{abstract}
Hypertrophic cardiomyopathy (HCM) is a genetic cardiac disorder. It is the most common reason of sudden cardiac death $(S C D)$ in young athletes. Prevention of these deaths is of high concern among physicians. Patients with high risk of SCD are canditates for implantable cardioverter device therapy. Cardiac imaging modalities provide important data in risk stratification for identifying HCM patients with high risk of SCD and interpreting the data obtained by different imaging modalities is important for prevention of SCD in this population. In this review, we evaluated the role of imaging modalities and their values in risk stratification of patients with HCM.
\end{abstract}

Keywords: Hypertrophic cardiomyopathy, sudden cardiac death, cardiac imaging modalities.

\section{Giriş}

Hipertrofik kardiyomiyopati (HKM) en sık görülen genetik kardiyomiyopatidir. Toplum genelinde görülme oranı \%0,2'dir (1). Otozomal dominant geçiş göstermekte olup hastalığın gelişimine neden olan sarkomerik genlerle ilişkili 600'den fazla mutasyon tanımlanmıştır (2). Hastalığın fizyopatolojisinde kardiyak hipertrofi, miyositlerin diziliminde bozulma, intertisyel aralıkta fibrozis ve intramiyokardiyal arteriyollerin displazisi rol almaktadır. Tanı temel olarak sol ventrikül (SV) hipertrofisi (SVH) varlığında SVH'ye sebep olabilecek aort darlığı ve hipertansiyon gibi diğer sebeplerin dışlanması ile konulmaktadır (3).

Yazışma Adresi: Kamil TÜLÜCE

Karşıyaka Devlet Hastanesi, Kardiyoloji Kliniği, İzmir, Türkiye Makalenin Geliş Tarihi: 20.03.2014 Kabul Tarihi: 24.07.2014
Hastalar genellikle klinik olarak asemptomatik olup tesadüfen fizik muayenede üfürüm ve/veya elektrokardiyografik (EKG) anormallik saptanması sonucu yapılan ekokardiyografi ile tanı almaktadırlar. Bazı hastalar ise nefes darlığı, göğüs ağrısı ve presenkop şikayeti ile başvurabilmektedirler. Klinik bulguların temelinde; diyastolik disfonksiyon, sol ventrikül çıkış yolunda tıkanıklık, miyokard iskemisi, mitral yetersizliği, atriyal ve ventriküler aritmiler ve otonom disfonksiyon yer almaktadır. Hipertrofik kardiyomiyopatinin en korkulan klinik seyri ani kardiyak ölümdür (AKÖ). Hastalar genel olarak normal yaşam sürelerini tamamlasalar da hastalıklı bireylerin \%1'inde AKÖ gelişebilmektedir (3). Ani kardiyak ölüm riskine sahip yüksek riskli bireylere "implante edilebilir kardiyoverter defibrilatör (ICD)" tedavisi uygulanmaktadır. Günümüzde HKM ile ilgili klinik çalışmalar, yüksek riskli hastaların seçimi ve tedavisi konusunda yoğunlaşmaktadır. Klasik risk faktörlerinin pozitif öngörü değeri düşüktür (Tablo-1). 
Tablo-1. Hipertrofik Kardiyomiyopatide Ani Kardiyak Ölüm Gelişiminde Kabul Gören Risk Faktörleri.

1. Hipertrofik kardiyomiyopati ile ilişkili 1 veya 1'den fazla ani
ölüm öyküsü
2. Son zamanlarda gelişen 1 veya 1 'den fazla açıklanamayan
senkop
3. Sol ventrikülde aşııı kalınlaşma ( $\geq 30 \mathrm{~mm}$ )
4. 24 saatlik Holter EKG'de süreksiz ventriküler taşikardi
5. Egzersize bağlı gelişen hipotansiyon ve azalmış kan
basıncı yanıtı

En az 1 risk faktörüne sahip olan birçok HKM hastasında AKÖ gelişmemektedir. Bu nedenlerden dolayı hekimler tarafından yeni belirteç arayışı devam etmektedir. Yeni geliştirilen görüntüleme yöntemleri ile birlikte kardiyak yapı ve fonksiyonun daha detaylı incelenmesine; dinamik obstrüksiyonun ciddiyetinin, mitral kapak anormalliklerinin, miyokard iskemisinin, miyokardiyal fibrozisin ve miyokard metabolizmasının değerlendirilmesine odaklanılmıştır (4). $\mathrm{Bu}$ derlemenin amacı, HKM'li hastaların klinik izleminde yüksek riskli bireylerin saptanmasında kullanılabilecek görüntüleme yöntemlerinin değerlendirilmesidir.

\section{Ekokardiyografi}

Transtorasik ekokardiyografi (TTE), HKM şüphesi olan hastaların başlangıç değerlendirilmesinde, takibinde ve taramasında sınıf I düzeyinde önerilen görüntüleme yöntemidir (3).

\section{M-mod ekokardiyografi}

Hipertrofik kardiyomiyopatide ilk tanısal ekokardiyografik kriter M-mod ekokardiyografi ile konulmuştur. İki boyutlu ekokardiyografi ile de gösterilebilen asimetrik septal hipertrofi, mitral kapağın sistolik öne hareketi (SÖH) (Şekil-1), küçük SV boyutu, septal hareketsizlik, aort kapağının erken kapanması M-mod ile saptanabilen bulgulardır (5). M-mod ile septum ve serbest duvarda sol ventrikül kalınlığının $15 \mathrm{~mm}$ üzerinde ölçülmesi ve septum/serbest duvar kalınlık oranının 1,3-1,5 ölçülmesi asimetrik septal hipertrofi olarak değerlendirilir.

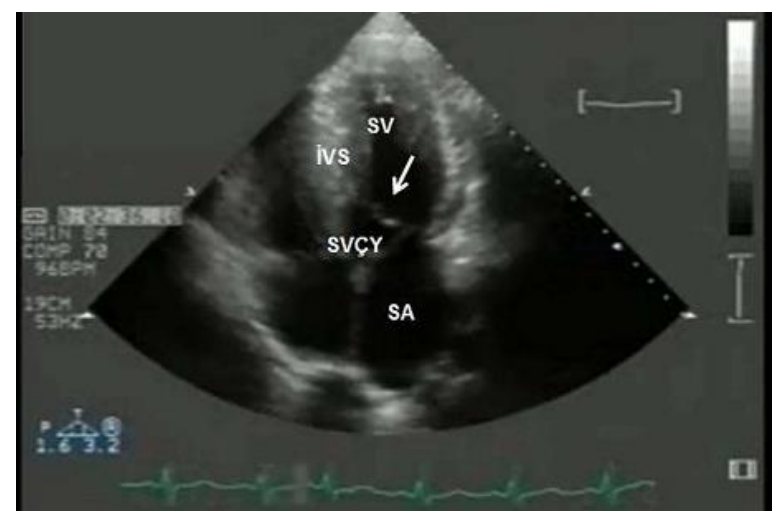

Şekil-1. Hipertrofik kardiyomiyopatili hastanın apikal dört boşluk görüntüsünde mitral kapağın sistolik öne hareketi (beyaz ok) görülmektedir. (IVS: Intervetriküler septum, SA: Sol atrium, SV: Sol ventrikül, SVÇY: Sol ventrikül çıkış yolu)
Mitral kapağın sistol esnasında öne doğru hareketi ile asimetrik septal hipertrofinin birlikteliği HKM için tanı koydurucu olarak kabul edilmekte iken, son yayınlanan yayınlarda yalancı sistolik öne hareketin (psödo-SÖH) hipertansiyon ve ön yükün düşük olduğu (anemi vb.) hiperdinamik sol ventrikülde de olabileceği gösterilmiştir (5-7).

\section{Ventrikül hipertrofisinin değerlendirilmesi}

Klasik olarak yetişkin toplumda HKM düşündürecek duvar kalınlığı değeri $\geq 15$ mm olarak kabul edilmiştir (8). Hipertrofik kardiyomiyopatinin ayırıcı tanısında, aort darlığı, atlet kalbi, mitokondrial hastalıklar, Fabry hastalığı, PRKAG2 mutasyonu, Danon hastalığı, glikojen depo hastalıkları, Noonan sendromu gibi hastalıklar yer almaktadır. Hipertrofik kardiyomiyopatide SV hipertrofisi genel olarak asimetrik olup anterior septum en çok etkilenen bölgedir. Olguların \%40'ında iki veya daha fazla segmentte hipertrofi gözlenmektedir (9). Bazı olgularda hipertrofi SV serbest duvarı veya apekste izole olarak da görülebilmektedir. Bu tip olgularda tanı için dikkatli bir görüntüleme gerekmektedir. Sol ventrikül apeksi tutulmuş olgularda (apikal HKM) intravenöz madde enjeksiyonu ile yapılan kontrast ekokardiyografi duvar sınırlarının net bir şekilde belirlenmesini sağlayarak doğru tanı konulmasını sağlamaktadır (10). Apikal HKM tanısında kardiyak manyetik rezonans görüntüleme $(\mathrm{KMR})$, kontrast ekokardiyografiye üstündür. Kontrast ekokardiyografi KMR'nin bulunmadığı merkezlerde veya çekilmesinin sakıncalı olduğu hastalarda sınıf Ila endikasyonla önerilmektedir (3).

Sol ventrikülün herhangi bir bölgesinde ölçülen maksimum duvar kalınlığının $\geq 30 \mathrm{~mm}$ olması uzun dönem risk belirteci olarak değerlendirilmiştir (Şekil-2) (11). Sol ventrikül hipertrofisinin derecesi yaşam boyu değişiklik göstermektedir. Sol ventrikül morfolojisinde en belirgin değişiklik ve artış ergenlik çağında görülmektedir. Bu nedenle aile bireylerine ergenlik çağında (12 ile $18-21$ yaş arası) yıllık, yetişkin çağda ise (>18-21 yaş) 5 yıl arayla ekokardiyografik takip önerilmektedir (3).

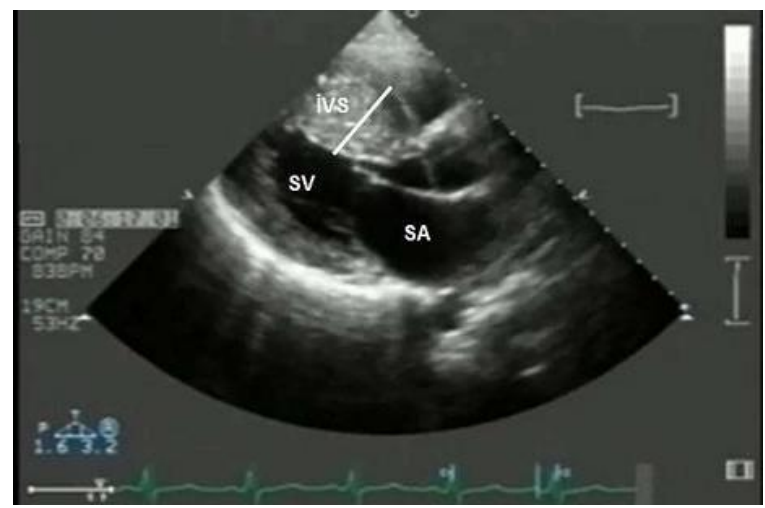

Şekil-2. Belirgin septal hipertrofisi (beyaz çizgi) olan bir hipertrofik kardiyomiyopatili hastanın parasternal uzun eksen görüntüsüdür. (IVS: İntervetriküler Septum, SA: Sol atrium, SV: Sol ventrikül) 
Sağ ventrikül (SaV) segmentlerinden iki veya daha fazlasının hipertrofiye olması sağ ventrikül hipertrofisi (SaVH) olarak tanımlanmaktadır. İki boyutlu ekokardiyografi ile SaVH'nin değerlendirilmesi güçtür. Hipertrofik kardiyomiyopatili hastaların birçoğunda hafif SaVH tespit edilmekle birlikte klinik ve prognostik önemi henüz bilinmemektedir (12).

\section{Sol ventrikül sistolik fonksiyonunun değerlendirilmesi}

Transtorasik ekokardiyografi, SV ejeksiyon fraksiyonunun (SVEF) değerlendirilmesinde ilk kullanılması gereken görüntüleme yöntemidir. Hipertrofik kardiyomiyopatili hastaların SVEF'si genel olarak normal veya artmıştır. Sol ventrikül EF'nin $<\% 50$ saptanması halinde buna son evre (burn out) HKM adı verilmektedir. Bu durum olguların \%2-5'inde görülmektedir ve oldukça kötü prognoz göstergesidir (13). Son dönem HKM olgularının sadece \%50'sinde SV kavitesinde bir miktar genişleme veya SV kalınlığında gerileme gözlenmektedir. Çok küçük bir grupta ise belirgin hipertrofi ile dilate olmamış bir ventrikülün birlikteliği görülebilmektedir (14).

\section{Doppler ekokardiyografi}

Sürekli dalga Doppler ekokardiyografi, HKM hastalarında sol ventrikül çıkış yolu (SVÇY) obstrüksiyonunun (SVÇYO) değerlendirilmesinde kullanılan temel yöntemdir (Şekil-3) (15). Hastaların yaklaşık \%25'inde istirahat halinde SVÇY'de $\geq 30 \mathrm{mmHg}$ zirve gradiyent saptanmaktadır. Bu durum obstrüktif HKM olarak adlandırılmaktadır. SVÇYO varlığı semptomatik durum, AF gelişme riski, embolik komplikasyonlar ve ölümle ilişkilidir. Hastaların çok küçük bir kısmında SVÇY gradiyentine SaV çıkış yolu gradiyenti de eşlik edebilmektedir (16). Obstrüktif HKM hastalarının büyük bir çoğunluğunda SÖH'e bağlı olarak gelişen mitral kapak 'koaptasyon' bozukluğuna bağlı olarak mitral yetersizlik görülmektedir. Renkli akım Doppler ekokardiyografi ile mitral yetersizliğinin varlığı ve derecesi belirlenebilmektedir. Sistolik öne hareket varlığında genel olarak mitral yetersizlik akımı sol atrium arka duvarına doğru olmaktadır (Şekil-4). Sol atriumun merkezine ve ön duvarına doğru uzanan mitral yetersizlik jet akımı yapısal mitral kapak hastalığını düşündürmelidir.

Diyastolik disfonksiyonun değerlendirilmesinde tartışmasız önerilen yöntem ekokardiyografidir. Diyastolik disfonksiyon neredeyse tüm HKM hastalarında görülmektedir. Diyastolik disfonksiyon ile miyokardiyal fibrozisin birbiriyle yakın ilişkili olduğu gözlenmiştir. HKM'li olgularda izovolümetrik gevşeme zamanı uzamış ve diyastolik erken doluş azalmıştır (17). Sol ventrikül sertliğinin artması ile birlikte sol atriumun ventrikül dolumuna katkısı artmıştır (18).

Diyastolik disfonksiyonun belirlenmesinde diğer bir yöntem doku Doppler ekokardiyografidir. Hipertrofik kardiyomiyopatili hastalarda diyastolde transmitral akım üzerinden elde edilen maksimum $E$ velositesinin erken diyastolde doku Doppler ile ölçülen $E^{\prime}$ velositesine oranının (E/E' oranı) sol ventrikül dolum basıncı ve egzersiz kapasitesi ile ilişkili olduğu belirlenmiştir (19). Septal E/E' oranının $\geq 15$ olmasının HKM hastalarında ani kardiyak ölüm ile ilişkili olduğu gösterilmiştir (20). Hipertrofik kardiyomiyopatili hastalarda diyastolik disfonksiyona bağlı olarak SV dolum basınçlarının artması sol atriumda (SA) yeniden şekillenmeye ve genişlemeye sebep olmaktadır. Sol atrium boyutları da HKM hastalarında önemli bir prognostik göstergedir (21). Sol atrium hacim ölçümü ön-arka duvar SA çap ölçümünden daha değerli bir yöntemdir (22). Sol atrium hacim indeksi (hacim/vücut yüzey alanı) hastalığın ciddiyeti ile doğrudan ilişkili olup SA hacim indeksinin $34 \mathrm{~mL} / \mathrm{m}^{2}$ üzerinde olduğu hastalarda ve SA hacminde yılda $>3 \mathrm{~mL}$ artış olan hastalarda prognozun daha kötü olduğu gösterilmiştir (23).

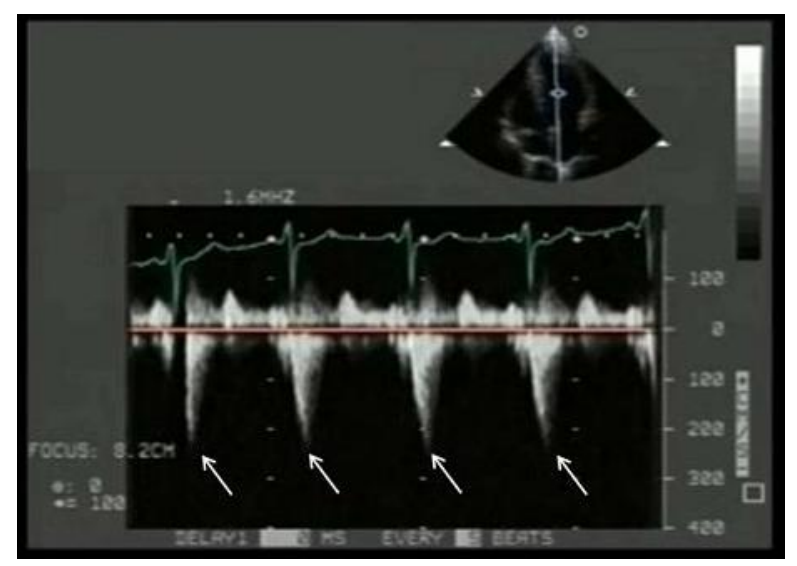

Şekil-3. İstirahatte sol ventrikül çıkış yolundan sürekli akım Doppler ile $35 \mathrm{mmHg}$ (beyaz oklar) gradiyent alınan hipertrofik obstrüktif kardiyomiyopatili hastanın görüntüsüdür.

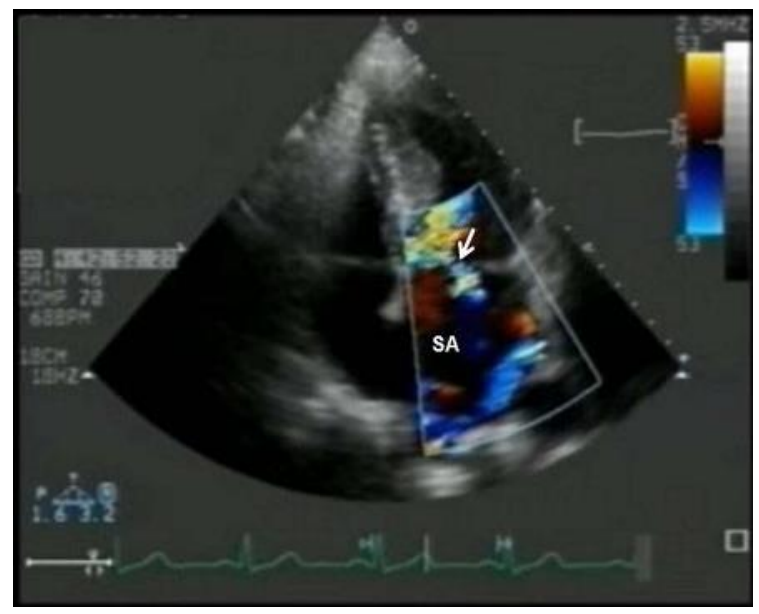

Şekil-4. Hipertrofik kardiyomiyopatili hastada mitral kapağın sistolik öne hareketine bağlı gelişen egzantrik mitral yetersizlik jeti (beyaz ok) görülmektedir. (SA: sol atrium) 


\section{Egzersiz ekokardiyografi}

İstirahat halinde SVÇYO saptanmayan olguların \%50'sinde egzersiz ile birlikte $\geq 30 \mathrm{mmHg}$ zirve gradiyent saptanmaktadır $(24,25)$. Egzersiz ekokardiyografi ile HKM hastalarının \%50'sinde sistolik disfonksiyon ve \%7,9'unda duvar hareket bozukluğu geliştiği gösterilmiştir (26). Egzersiz ekokardiyografide çok değişkenli analizler sonucunda HKM hastalarında maksimum duvar kalınlığı, metabolik eşdeğer (MET), dinlenim ve egzersiz duvar hareket skor indeksi majör kardiyak olaylar açısından bağımsız risk faktörleri olarak belirlenmiştir (27).

Egzersiz TTE, istirahat halinde obstrüksiyon tespit edilmeyen olgularda dinamik obstrüksiyonun ortaya konmasında ve obstrüksiyon derecesinin belirlenmesinde sınıf lla kanıt düzeyi ile önerilmektedir (3).

\section{Strain (gerilme) görüntüleme}

Hipertrofik kardiyomiyopatili hastalarda hipertrofiye olmuş ve sertleşmiş duvarlarda anatomik bütünlüğün bozulduğu, kalsiyum ve glukoz metabolizmasının değiştiği, subendokardiyal iskemiye bağlı olarak miyokardiyal duvar hareketlerinde farklılıklar oluştuğu gözlenmiştir (28). Bu farklılıklar normal sistolik fonksiyonlara sahip HKM hastalarında dahi görülebilmektedir. Özellikle ciddi şekilde hipertrofiye olmuş segmentlerde longitudinal ve radiyal sistolik miyokardiyal deformasyon azalmıştır (29). Benek takibi (speckle tracking) ekokardiyografi tekniği ile miyokardın burkulma hareketleri kantitatif olarak incelenebilmektedir. Hipertrofik kardiyomiyopatili hastalarda SV orta bölgesinin dönüşü saat yönünde iken normal bireylerde ise ters yönde olmaktadır (30). 'Strain rate' görüntüleme tekniği ile hipertansiyona bağlı gelişen SV hipertrofisi ile HKM'ye bağlı SV hipertrofisi ayırt edilebilmektedir (31). 'Strain' görüntüleme SA fonksiyonlarının değerlendirilmesinde de oldukça değerlidir. Doku Doppler ve iki boyutlu "strain" ile yapılmış incelemelerde atrium fonksiyonlarının HKM hastalarında diğer ikincil nedenlerle ilişkili hipertrofi hastalarına göre daha fazla azaldığı gösterilmiştir (32). "Strain" ekokardiyografinin HKM'li hastalarda prognozun belirlemesindeki yeri şu an için net olarak bilinmemektedir.

\section{Kardiyak manyetik görüntüleme}

Kardiyak MR, HKM araştırmalarının en umut vaat eden görüntüleme yöntemidir. Kardiyak MR her iki ventrikülün fonksiyonlarının, duvar kalınlıklarının ve miyokardiyal doku karakterizasyonunun doğru ve net bir şekilde tanımlanmasını sağlamaktadır. Son zamanlarda KMR sayesinde HKM'de yeni bakış açıları geliştirilmiş ve kötü prognostik etki oluşturabilecek bir dizi yeni belirteçler bulunmuştur $(33,34)$.

Kardiyak MR, endokardiyal sınırların belirlenmesinde ve miyokard segmentlerinin hipertrofi açısından değerlen- dirilmesinde TTE'ye göre daha üstündür. Özellikle apikal HKM ve mid-ventriküler HKM'ye ikincil gelişen apikal anevrizmalar TTE ile sıklıkla gözden kaçmaktadır. Hipertrofik kardiyomiyopati tanısının ekokardiyografi ile net konulamadığı vakalarda sınıf I endikasyonla KMR önerilmektedir (3). Kardiyak MR, kötü prognostik faktör olarak değerlendirilen miyokardiyal fibrozisin değerlendirilmesinde en üstün yöntemdir (35).

\section{Ventrikül hipertrofisinin değerlendirilmesi}

Hipertrofik kardiyomiyopatili hastaların \%12'sinde hipertrofi bölgeseldir. Kalbin en sık bölgesel hipertrofi görülen alanları TTE ile değerlendirilmesi en zor olan anterolateral serbest duvar, posterior duvar, septum ve apekstir. Moon ve ark. (36) yaptığı bir çalışmada, EKG anormallikleri nedeniyle HKM açısından TTE ile değerlendirilip negatif saptanan 10 olguda KMR ile apeks veya lateral duvara lokalize HKM tanısı konulmuştur. Kardiyak MR, SV kitlesinin değerlendirilmesinde en ideal yöntemdir. Kardiyak MR ile ölçülen SV kitlesinin HKM hastalarında klinik sonlanım açısından hassas bir öngördürücü olduğu gösterilmiştir $(37,38)$.

Sağ ventrikülün retrosternal yerleşiminden dolayı TTE ile net bir şekilde değerlendirilmesi oldukça zordur. Bu nedenle KMR SaV'nin değerlendirilmesinde TTE'den daha avantajılıd (33). Kardiyak MR ile HKM hastalarının \%20'sinde TTE ile ölçülen maksimum duvar kalınlığında ( $\geq 8 \mathrm{~mm}$ ) artış saptanmıştır (33).

\section{Geç gadolinyum tutulumu}

Gadolinyumlu KMR HKM'de oldukça fazla görülen intertisiyel fibrozisin görüntülenmesinde değerli bir yöntemdir. Gadolinyum fibrozisli alanlarda birikir ve daha geç temizlenir. Geç gadolinyum tutulum (GGT) miktarı ile kollajen yüzdesi arasında doğrudan bir ilişki bulunmaktadır (39). Gadolinyumun dağılım özelliği nedeniyle vasküler nedenli iskemi ile vasküler nedenli olmayan iskeminin ayrımı sağlanabilmektedir (40). İskemik nedenli olmayan gadolinyum tutulumu vasküler perfüzyon alanından bağımsız olup subendokardiyal bölgede olmaktadır. İskemik nedenli gadolinyum tutulumu doğrudan vasküler beslenme alanı ile ilişkili olup subendokardiyal veya transmuraldir (41).

Hipertrofik kardiyomiyopatili hastalarda miyokardiyal fibrozisin aritmiye yatkınlık oluşturduğu düşünülmektedir. Nitekim GGT miktarı ile 24 saatlik Holter EKG kayıtlarında elde edilen ventriküler aritmileri arasında kanıtlanmış bir ilişki bulunmaktadır $(42,43)$. İleriye dönük bazı çalışmalarda AKÖ gelişen veya uygun ICD şoklaması alan HKM hastalarında GGT'nin daha fazla görüldüğü belirlenmiştir (44). Hipertrofik kardiyomiyopatili hastaların yaklaşık \%65'inde fibrozisin kanıtı olan GGT saptanması nedeniyle GGT'nin tek başına pozitif olmasının kardiyak olayları ön görmede iyi bir parametre olamayacağını düşünülmektedir (45). Eldeki mevcut veriler bu konuda yapılmış geniş çaplı ileriye dönük çalışma yapılmamış olmasından dolayı GGT'nin AKÖ açısından tek bağımsız 
risk faktörü olamayacağını belirtmektedir (45). Fakat yine de bazı otörler GGT'yi ICD takılması kararı açısından orta risk grubuna sokmayı tercih etmişlerdir (46).

Seçilmiş hastalarda AKÖ için kullanılan temel risk faktörlerinin aydınlatıcı olmadığı durumlarda GGT'yi değerlendiren KMR sınıf Ilb endikasyonla önerilmektedir (3).

\section{Sol ventrikül çıkış yolu obstrüksiyonu}

HKM hastalarında SVÇY obstrüksiyonunda mitral kapak altı yapıların önemli etkisi bulunmaktadır. Özellikle anterior papiller kasın normal hastalara göre farklı yerleşimi gibi papiller kas anormalliklerinin yüksek oranda bulunması bu durumu destekler niteliktedir (4749). Kardiyak MR mitral kapak ve papiller kas yapılarının değerlendirilmesinde, mitral ön yaprağın septuma temas noktasının tespitinde ve HKM ile karışabilecek SVÇY gradiyenti oluşturan tablolardan biri olan subaortik membranın tanısında da değerli bir yöntemdir. Bu yapıların TTE ile net değerlendirilemediği durumlarda sınıf I endikasyonla KMR önerilmektedir (3).

\section{İskemi}

İskemi testleri HKM hastalarında tanı testlerinden biri olarak değerlendirilmemektedir. Fakat ileri dönem risk belirteci olarak kullanılabilmektedir. Negatif yeniden şekillenme gelişmeden önce iskeminin belirlenmesinin ve tedavisine odaklanılmasının HKM'nin doğal seyrini olumlu yönde etkileyebileceği düşünülmektedir (50). İskeminin HKM'de iki önemli sekeli mevcuttur ve bunlar prognostik açıdan önemlidir. Mid-ventriküler hipertrofisi olan hastalarda darlık bölgesindeki gradiyentle beraber kronik mikrovasküler iskeminin varlığı apikal duvarın incelmesine ve hatta anevrizma gelişmesine sebep olmaktadır. Bu duruma tükenmiş apeks (burn out apex) adı verilmektedir (Şekil-5) (51). Apikal anevrizma gelişenlerde yıllık kardiyak olay gelişimi \%10'a çıkmaktadır (51). Ayrıca apikal anevrizma gelişimi SV'de trombüs gelişimine de sebep olabilmektedir.

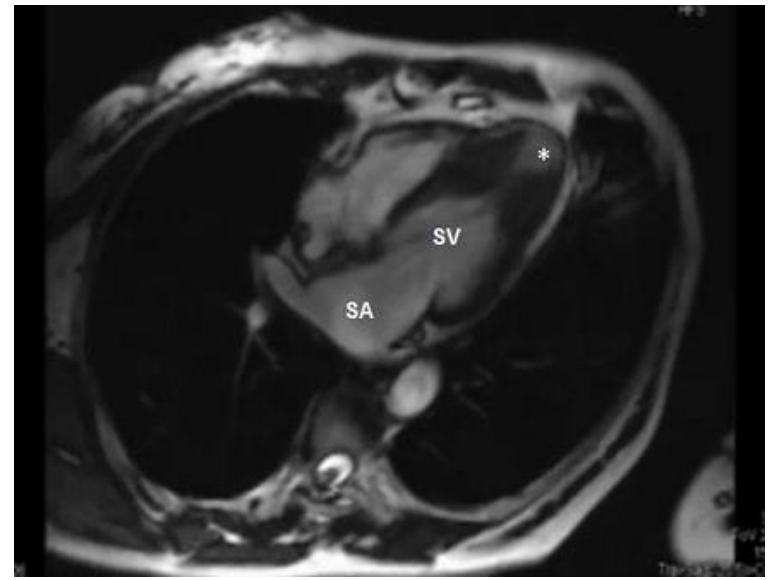

Şekil-5. Mid-ventriküler hipertrofisi olan bir hastada kardiyak manyetik rezonans görüntülemede saptanan apikal anevrizma (asteriks) görülmektedir. (SA: Sol atrium SV: Sol ventrikül.

Cilt 54 Sayı 4, Aralık 2015 / Volume 54 Issue 4, December 2015
Hipertrofik kardiyomiyopatide risk değerlendirilmesinde yeni KMR teknikleri geliştirilmekte olup klinik açıdan değer kazanabilmesi için daha fazla çalışmaya gerek vardır. T1 haritalama tekniği standart GGT tekniğine göre fibrozisin değerlendirilmesinde daha hassastır (52). 'Kardiyak manyetik rezonans spektroskopi' tekniği miyokardiyal dokunun enerji durumunu belirlemektedir (53). Ayrıca "vasküler stifness tekniği" ile aort sertliği değerlendirilmektedir. Aortik sertliğin HKM'de risk sınıflandırmasında önemli bir parametre olabileceği düşünülmektedir (54).

\section{Nükleer görüntüleme}

Gated blood-pool radyonüklid anjiyografi, SV ve SaV hacimlerinin ve aynı zamanda EF'lerinin değerlendirilmesini sağlar. Radyonüklid anjiyografi ile aynı zamanda ventrikülün asimetrik hipertrofisi değerlendirilebilmektedir. Ekokardiyografi ve KMR'nin yüksek uzaysal çözünürlüğü nedeniyle nükleer incelemeye bu amaçla pek gerek duyulmamaktadır (3).

Nükleer yöntemler ile HKM hastalarında iskeminin varlığı ve ciddiyeti tespit edilebilir. Talyumla tespit edilebilen bölgesel perfüzyon bozukluğu prognostik açıdan önemlidir (55,56). Fakat "single photon emition computed tomography (SPECT)" ile belirlenen iskemik perfüzyon defektlerinin varlığı epikardiyal koroner lezyonların tespiti açısından yalancı pozitifliğe neden olmaktadır (57). Hipertrofik kardiyomiyopatili hastalarda rutin olarak SPECT önerilmemekle birlikte göğüs ağrısı olup koroner arter hastalığı açısından düşük olasılıklı hastalarda sınıf Ila endikasyonla düşünülebilir (3)

\section{Pozitron emisyon tomografisi}

Pozitron emisyon tomografisi (PET) kardiyovasküler araştırmalarda bölgesel kan akımının değerlendirilmesinde önemli yere sahiptir. Pozitron emisyon tomografisi çalışmalarında HKM hastalarında koroner akım rezervinin normal hastalara göre azaldığı belirlenmiştir ve bu durum kötü prognostik göstergesi olarak değerlendirilmektedir (58). Günlük klinik pratikte rutin iskemi değerlendirilmesi amacıyla HKM hastalarına PET inceleme yapılmamaktadır.

Gelecek açısından miyokardiyal metabolizmayı, sempatik innervasyonu ve $\beta$ adrenerjik reseptör yoğunluğunu belirleyebilmek amacıyla yeni radyofarmasötik ajanlar denenmektedir. Bu yöntemlerin etkinliği ile HKM'nin patofizyolojisi, kalp yetersizliği ve AKÖ açısından riskli grupların tespiti mümkün olabilecektir (59-63).

\section{Bilgisayarlı tomografi}

Bilgisayarlı tomografinin (BT) yüksek kontrast rezolüsyonu sayesinde HKM'li hastalarda duvar kalınlıklarının doğru ölçümü, ventriküler hacmin, miyokard kitlesinin, miyokard duvar sınırlarının ve HKM fenotipinin tespiti mümkün olabilmektedir $(64,65)$. Kardiyak BT ile eş zamanlı olarak koroner anatomi ve "miyokardiyal bridge" 
varlığı da değerlendirilebilmektedir (66).

Kardiyak BT'nin HKM hastalarında TTE ve KMR ile birebir karşılaştırılmasının olmaması nedeniyle rutin kullanımı önerilmemektedir. Suboptimal TTE görüntüsü olan ve sakıncalı bir durumun olması nedeniyle KMR çekilememiş hastalarda BT kullanılabilir. Bu durumlarda geriye dönük elektrokardiyografik sinyal ayırıcı yöntemin (retrospektif gated) yüksek radyasyon maruziyetine sebep olması nedeniyle kullanılmamalı; bunun yerine ileriye dönük (prospektif) inceleme tekniği uygulanmalıdır (67).

Tablo-2. Ani Kardiyak Ölüm İçin Risk Faktörleri ve Seçilecek Görüntüleme Yöntemleri.

\begin{tabular}{ll}
\hline \multicolumn{1}{c}{ Risk faktörleri } & \multicolumn{1}{c}{ Görüntüleme yöntemleri } \\
\hline Maksimum duvar kalınlığı $\geq 3 \mathrm{~cm}$ & TTE, KMR, Kardiyak BT \\
SA hacim indeksi > $34 \mathrm{~mL} / \mathrm{m}^{2}$ & TTE, KMR, Kardiyak BT \\
SVEF $(<\% 50)$ & TTE,radyonüklid anjiyografi, \\
& KMR, Kardiyak BT \\
Apikal anevrizma & Kontrast ekokardiyografi, \\
SVÇY gradiyent $\geq 30 \mathrm{~mm} \mathrm{Hg}$ & KMR, Kardiyak BT \\
Perfüzyon defekti & Doppler ekokardiyografi \\
Azalmış koroner akım rezervi & SPECT \\
Geç gadolinyum tutulumu & PET \\
\hline
\end{tabular}

\section{Sonuç}

Hipertrofik kardiyomiyopatide risk sınıflandırılmasında görüntüleme yöntemleri oldukça önemli bir yere sahiptir. Sol ventrikül hipertrofisi dışında, SA genişlemesi, son dönem kalp yetersizliği, apikal anevrizma, SVÇY gradiyentinin $30 \mathrm{mmHg}$ 'nin üzerinde olması, perfüzyon defekti, azalmış koroner akım rezervi, geç gadolinyum tutulumu görüntüleme yöntemleri ile saptanabilen ani ölüm risk belirteçleridir (Tablo-2) (68).

Ekokardiyografi genel olarak ilk başvurulan görüntüleme yöntemi olmakla beraber KMR, BT, PET ve nükleer incelemelerin bazı durumlarda avantajı yönleri bulunmaktadır. Kardiyak MR SV fonksiyonlarının, duvar kalınlığının, SVÇY obstrüksiyonunun, mitral yetersizliğinin, SA hacminin değerlendirilmesinde TTE'ye alternatif bir yöntem olup miyokardiyal fibrozisin değerlendirilmesinde ise altın standart görüntüleme yöntemidir. Miyokardiyal iskeminin değerlendirilmesinde BT ve nükleer incelemeler önerilmektedir. Günümüzde her şeye rağmen HKM hastalarında gelişebilecek istenmeyen olayların öngörülmesinde kullanılacak yeni parametrelere intiyaç olup bu konuda yapılacak büyük ve ileriye dönük çalışmalara intiyaç vardır.

\section{Kaynaklar}

1. Maron BJ. Hypertrophic cardiomyopathy: A systematic review. JAMA 2002;287(10):1308-20.

2. Bos JM, Towbin JA, Ackerman MJ. Diagnostic, prognostic, and therapeutic implications of genetic testing for hypertrophic cardiomyopathy. J Am Coll Cardiol 2009;54(3):201-11.

3. Gersh BJ, Maron BJ, Bonow RO, et al. 2011 ACCF/AHA Guideline for the Diagnosis and Treatment of Hypertrophic Cardiomyopathy: a report of the American College of Cardiology Foundation/American Heart Association Task Force on Practice Guidelines. Developed in collaboration with the American Association for Thoracic Surgery, American Society of Echocardiography, American Society of Nuclear Cardiology, Heart Failure Society of America, Heart Rhythm Society, Society for Cardiovascular Angiography and Interventions, and Society of Thoracic Surgeons. J Am Coll Cardiol 2011;58(25):212-60.

4. Maron BJ. Risk stratification and role of implantable defibrillators for prevention of sudden death in patients with hypertrophic cardiomyopathy. Circ J 2010;74(11):2271-82.

5. Maron BJ, Towbin JA, Thiene G, et al. Contemporary definitions and classification of the cardiomyopathies. Circulation 2006;113(14):1807-16

6. Doi YL, McKenna WJ, Oakley CM, et al. 'Pseudo' systolic anterior motion in patients with hypertensive heart disease. Eur Heart J 1983;4(12):838-45.

7. Mun JB, Oh AR, Park HS, et al. The Unusual Suspect: Anemia-induced Systolic Anterior Motion of the Mitral Valve and Intraventricular Dynamic Obstruction in a Hyperdynamic Heart as Unexpected Causes of Exertional Dyspnea after Cardiac Surgery. Korean J Thorac Cardiovasc Surg 2013;46(6):457-60.

8. Spirito $\mathrm{P}$, Maron BJ, Chiarella F, et al. Diastolic abnormalities in patients with hypertrophic cardiomyopathy: Relation to magnitude of left ventricular hypertrophy. Circulation 1985;72(2):310-6.

9. Klues HG, Schiffers A, Maron BJ. Phenotypic spectrum and patterns of left ventricular hypertrophy in hypertrophic cardiomyopathy morphologic observations and significance as assessed by two-dimensional echocardiography in 600 patients. J Am Coll Cardiol 1995;26(7):1699-708.

10. Olszewski R, Timperley J, Szmigielski C, et al. The clinical applications of contrast echocardiography. Eur J Echocardiogr 2007;8(3):13-23

11. Spirito $\mathrm{P}$, Bellone $\mathrm{P}$, Harris $\mathrm{KM}$, et al. Magnitude of left ventricular hypertrophy and risk of sudden death in hypertrophic cardiomyopathy. N Engl J Med 2000;342(24):1778-85.

12. Maron MS, Hauser TH, Dubrow E, et al. Right ventricular involvement in hypertrophic cardiomyopathy. Am J Cardiol 2007;100(8):1293-8.

13. Thaman R, Gimeno JR, Murphy RT, et al. Prevalence and clinical significance of systolic impairment in hypertrophic cardiomyopathy. Heart 2005;91(7):920-5

14. Harris KM, Spirito $P$, Maron MS, et al. Prevalence, clinical profile, and significance of left ventricular remodeling in the end-stage phase of hypertrophic cardiomyopathy. Circulation 2006;114(3):216-25. 
15. Panza JA, Petrone RK, Fananapazir L, et al. Utility of continuous wave Doppler echocardiography in the noninvasive assessment of left ventricular outflow tract pressure gradient in patients with hypertrophic cardiomyopathy. J Am Coll Cardiol 1992;19(1):91-9.

16. Maron BJ, McIntosh CL, Klues HG, et al. Morphologic basis for obstruction to right ventricular outflow in HCM. Am J Cardiol 1993;71(12):1089-94.

17. Nagueh SF, Lakkis NM, Middleton KJ, et al. Doppler estimation of left ventricular filling pressures in patients with hypertrophic cardiomyopathy. Circulation 1999;99(2):254-61.

18. Tülüce K, Tülüce SY, Yavuzgil O, et al. The left atrial phasic functions and the relationship with plasma N-terminal pro-B-type natriuretic peptide levels and symptomatic states in patients with hypertrophic cardiomyopathy. Anadolu Kardiyol Derg 2014;14(8):719-27.

19. Kitaoka H, Kubo T, Okawa M, et al. Utility of tissue Doppler imaging to predict exercise capacity in hypertrophic cardiomyopathy: Comparison with B-type natriuretic peptide. J Cardiol 2009;53(3):361-7.

20. Efthimiadis GK, Giannakoulas G, Parcharidou DG, et al. Clinical significance of tissue Doppler imaging in patients with hypertrophic cardiomyopathy. Circ J 2007;71(6):897-903.

21. Nistri S, Olivotto I, Betocchi S, et al. Prognostic significance of left atrial size in patients with hypertrophic cardiomyopathy (from the Italian Registry for Hypertrophic Cardiomyopathy). Am J Cardiol 2006;98(7):960-5.

22. Pritchett AM, Jacobsen SJ, Mahoney DW, et al. Left atrial volume as an index of left atrial size: A population-based study. J Am Coll Cardiol 2003;41(6):1036-43.

23. Losi MA, Betocchi S, Barbati G, et al. Prognostic significance of left atrial volume dilatation in patients with hypertrophic cardiomyopathy. J Am Soc Echocardiogr 2009;22(1):76-81.

24. Maron MS, Olivotto I, Zenovich AG, et al. Hypertrophic cardiomyopathy is predominantly a disease of left ventricular outflow tract obstruction. Circulation 2006;114(21):2232-9.

25. Shah JS, Esteban MT, Thaman R, et al. Prevalence of exercise-induced left ventricular outflow tract obstruction in symptomatic patients with non-obstructive hypertrophic cardiomyopathy. Heart 2008;94(10):1288-94.

26. Okeie K, Shimizu M, Yoshio H, et al. Left ventricular systolic dysfunction during exercise and dobutamine stres in patients with hypertrophic cardiomyopathy. J Am Coll Cardiol 2000;36(3):856-63.

27. Peteiro J, Bouzas-Mosquera A, Fernandez X, et al. Prognostic value of exercise echocardiography in patients with hypertrophic cardiomyopathy. J Am Soc Echocardiogr 2012;25(2):182-9.

28. Nagueh SF, Mahmarian JJ. Noninvasive cardiac imaging in patients with hypertrophic cardiomyopathy. J Am Coll Cardiol 2006;48(12):2410-22.

29. Ganame J, Mertens L, Eidem BW, et al. Regional myocardial deformation in children with hypertrophiccardiomyopathy: morphological and clinical correlations. Eur Heart J 2007;28(23):2886-94.

30. Carasso S, Yang H, Woo A, et al. Systolic myocardial mechanics in hypertrophic cardiomyopathy: Novel concepts and implications for clinical status. J Am Soc Echocardiogr 2008;21(6):675-83.

31. Kato TS, Noda A, Izawa $\mathrm{H}$, et al. Discrimination of nonobstructive hypertrophic cardiomyopathy from hypertensive left ventricular hypertrophy on the basis of strain rate imaging by tissue Doppler ultrasonography. Circulation 2004;110(25):3808-14.

32. Paraskevaidis IA, Panou F, Papadopoulos $C$, et al. Evaluation of left atrial longitudinal function in patients with hypertrophic cardiomyopathy: a tissue Doppler imaging and two-dimensional strain study. Heart 2009;95(6):483-9.

33. To ACY, Dhillon A, Desai MY. Cardiac magnetic resonance in hypertrophic cardiomyopathy. JACC Cardiovasc Imag 2011;4(10):1123-37

34. Kwon DH, Smedira NG, Rodriguez ER, et al. Cardiac magnetic resonance detection of myocardial scarring in hypertrophic cardiomyopathy: Correlation with histopathology and prevalence of ventricular tachycardia. J Am Coll Cardiol 2009;54(3):242-9.

35. O'Hanlon R, Grasso A, Roughton M, et al. Prognostic significance of myocardial fibrosis in hypertrophic cardiomyopathy. J Am Coll Cardiol 2010;56(11):867-74.

36. Moon JC, Fisher NG, McKenna WJ, et al. Detection of apical hypertrophic cardiomyopathy by cardiovascular magnetic resonance in patients with non-diagnostic echocardiography. Heart 2004;90(6):645-9.

37. Pennell DJ. Ventricular volume and mass by CMR. J Cardiovasc Magn Reson 2002;4(4):507-13.

38. Elliott PM, Gimeno Blanes JR, Mahon NG, et al. Relation between severity of left-ventricular hypertrophy and prognosis in patients with hypertrophic cardiomyopathy. Lancet 2001;357(9254):420-4.

39. Moon JC, Reed E, Sheppard MN, et al. The histologic basis of late gadolinium enhancement cardiovascular magnetic resonance in hypertrophic cardiomyopathy. J Am Coll Cardiol 2004;43(12):2260-4.

40. Kim RJ, Fieno DS, Parrish TB, et al. Relationship of MRI delayed contrast enhancement to irreversible injury, infarct age, and contractile function. Circulation 1999;100(19):1992-2002.

41. Hoey ETD, Gulati GS, Ganeshan A, et al. Cardiovascular MRI for assessment of infectious and inflammatory conditions of the heart. AJR Am J Roentgenol 2011;197(1):103-12.

42. Adabag AS, Maron BJ, Appelbaum E, et al. Occurrence and frequency of arrhythmias in hypertrophic cardiomyopathy in relation to delayed enhancement on cardiovascular magnetic resonance. J Am Coll Cardiol 2008;51(14):1369-74.

43. Fluechter S, Kuschyk J, Wolpert C, et al. Extent of late gadolinium enhancement detected by cardiovascular magnetic resonance correlates with the inducibility of ventricular tachyarrhythmia in hypertrophiccardiomyopathy. J Cardiovasc Magn Reson 2010;12(1):30.

44. Bruder $\mathrm{O}$, Wagner $\mathrm{A}$, Jensen $\mathrm{CJ}$, et al. Myocardial scar visualized by cardiovascular magnetic resonance imaging predicts major adverse events in patients with hypertrophic cardiomyopathy. J Am Coll Cardiol 2010;56(11):875-87.

45. Maron MS, Appelbaum E, Harrigan CJ, et al. Clinical profile and significance of delayed enhancement in hypertrophic cardiomyopathy. Circ Heart Fail 2008;1(3):184-91.

46. Maron BJ. Contemporary insights and strategies for risk stratification and prevention of sudden death in hypertrophic cardiomyopathy. Circulation 2010;121(3):445-56. 
47. Maron MS, Olivotto I, Harrigan C, et al. Mitral valveabnormalities identified by cardiovascular magnetic resonance represent a primary phenotypic expression of hypertrophic cardiomyopathy. Circulation 2011;124(1):40-7.

48. Kwon DH, Setser RM, Thamilarasan M, et al. Abnormal papillary muscle morphology is independently associated with increased left ventricular outflow tract obstruction in hypertrophic cardiomyopathy. Heart 2008;94(10):1295-301.

49. Harrigan CJ, Appelbaum E, Maron BJ, et al. Significance of papillarymuscle abnormalities identified by cardiovascular magnetic resonance in hypertrophic cardiomyopathy. Am J Cardiol 2008;101(5):668-73.

50. Maron MS, Olivotto I, Maron BJ, et al. The case for myocardial ischemia in hypertrophic cardiomyopathy: an emerging but under-recognized pathophysiologic mechanism. J Am Coll Cardiol 2009;54(9):866-75.

51. Maron MS, Finley JJ, Bos JM, et al. Prevalence, clinical significance, and natural history of left ventricular apical aneurysms in hypertrophic cardiomyopathy. Circulation 2008;118(15):1541-9.

52. Amano Y, Takayama M, Kumita S. Contrast-enhanced myocardial T1-weighted scout (Look-Locker) imaging for the detection of myocardial damages in hypertrophic cardiomyopathy. J Magn Reson Imaging 2009;30(4):778-84.

53. Holloway CJ, Suttie J, Dass S, et al. Clinical cardiac magnetic resonance spectroscopy. Prog Cardiovasc Dis 2011;54(3):320-7.

54. Austin BA, Popovic ZB, Kwon DH, et al. Aortic stiffness independently predicts exercise capacity in hypertrophic cardiomyopathy: a multimodality imaging study. Heart 2010;96(16):1303-10.

55. O'Gara PT, Bonow RO, Maron BJ, et al. Myocardial perfusion abnormalities in patients with hypertrophic cardiomyopathy: assessment with thallium-201 emission computed tomography. Circulation 1987;76(6):1214-23.

56. Dilsizian V, Bonow RO, Epstein SE, et al. Myocardial ischemia detected by thallium scintigraphy is frequently related to cardiac arrest and syncope in young patients with hypertrophic cardiomyopathy. J Am Coll Cardiol 1993;22(3):796-804.

57. Nagueh SF, Mahmarian JJ. Noninvasive cardiac imaging in patients withhypertrophic cardiomyopathy. J Am Coll Cardiol 2006;48(12):2410-22.

58. Camici $\mathrm{P}$, Chiriatti $\mathrm{G}$, Lorenzoni $\mathrm{R}$, et al. Coronary vasodilation is impaired in both hypertrophied and nonhypertrophied myocardium of patients with hypertrophic cardiomyopathy: a study with nitrogen-13 ammonia and positron emission tomography. J Am Coll Cardiol 1991;17(4):879-86.

59. Zhao C, Shuke N, Okizaki A, et al. Comparison of myocardial fatty acid metabolism with left ventricular function and perfusion in cardiomyopathies by 123I-BMIPP SPECT and 99mTc-tetrofosmin electrocardiographically gated SPECT. Ann Nucl Med 2003;17(7):541-8.

60. Terai $\mathrm{H}$, Shimizu $\mathrm{M}$, Ino $\mathrm{H}$, et al. Changes in cardiac sympathetic nerve innervations and activity in pathophysiologic transition from typical to end-stage hypertrophic cardiomyopathy. J Nucl Med 2003;44(10):1612-7.

61. Schafers M, Durka D, Rhodes CG, et al. Myocardial presynaptic and postsynaptic autonomic dysfunction in hypertrophic cardiomyopathy. Circ Res 1998;82(1):57-62.

62. Sipola P, Vanninen E, Aronen HJ, et al. Cardiac adrenergic activity is associated with left ventricular hypertrophyin genetically homogeneous subjects with hypertrophic cardiomyopathy. J Nucl Med 2003;44(4):487-93

63. Choudhury L, Guzzetti S, Lefroy DC, et al. Myocardial beta adrenoceptors and left ventricular function in hypertrophic cardiomyopathy. Heart 1996;75(1):50-4.

64. Orakzai $\mathrm{SH}$, Orakzai $\mathrm{RH}$, Nasir $\mathrm{K}$, et al. Assessment of cardiac function using multidetector row computed tomography. $\mathrm{J}$ Comput Assist Tomogr 2006;30(4):555-63.

65. Dewey M, Müller M, Eddicks S, et al. Evaluation of global and regional left ventricular function with 16-slice computed tomography, biplane cine ventriculography, and two dimensional transthoracic echocardiography: Comparison with magnetic resonance imaging. J Am Coll Cardiol 2006;48(10):2034-44.

66. Mao SS, Budoff MJ, Oudiz RJ, et al. Effect of exercise on left and right ventricular ejection fraction and wall motion in patients with coronary artery disease: An electron beam computed tomography study. Int J Cardiol 1999;71(1):23-31.

67. Gopal A, Mao SS, Karlsberg D, et al. Radiation reduction with prospective ECG-triggering acquisition using 64-multidetector computed tomographic angiography. Int J Cardiovasc Imaging 2009;25(4):405-16.

68. Nagueh SF, Bierig SM, Budoff MJ, et al. American Society of Echocardiography clinical recommendations for multimodality cardiovascular imaging of patients with hypertrophic cardiomyopathy: Endorsed by the American Society of Nuclear Cardiology, Society for Cardiovascular Magnetic Resonance, and Society of Cardiovascular Computed Tomography. J Am Soc Echocardiogr 2011;24(5):473-98. 